\title{
DUES RONDALLES TAMBÉ VALENCIANES: «EL SOLDAT DE LA MOTXILLA»I «EL TEULADÍ I EL RABIBLANC» Vicent Vidal Lloret
}

\author{
Senyor, feume la gracia de que'l que puje a \\ la perera no puga abaixar fins a que yo no \\ li hu mane. \\ FRANCESC MARTÍNEZ I MARTÍNEZ, \\ «Misèria»
}

\section{INTRODUCCIÓ}

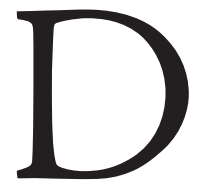

es d'aquell moment, tothom que pugés a la perera de la tia Misèria ja no en podria descendir sense el consentiment de la vella. És així que va enganyar la mateixa Mort $i$, abans d'alliberar-la, li posà una condició: que mai no la perseguís. És per això que la Misèria continua i continuarà viva. Aquesta és la nostra capsa de Pandora, la nostra serp que temptà Eva al Paradís. La nostra i la de milers d'europeus que s'expliquen —o s'explicaven - els mals del món d'aquesta manera. Això ho sabem gràcies als estudis rigorosos que, al llarg del segle XX i del que tenim vist del XXI, han descobert $i$ han demostrat quelcom d'extraordinari: que la literatura més universal és la tradicional, la popular, la transmesa entre generacions de manera oral. Que un mateix conte s'explique, amb poca variació, des del nas de Portugal fins a Índia mateix és tan esborronador com que s'hi hagués parlat, en algun moment, una mateixa llengua que avui anomenem indoeuropeu. I, tanmateix, no n'hi pot haver cap dubte. Ens ho confirmen Aarne i Thompson (1995) i Uther (2004), que, a partir d'un buidatge monumental, n'estudiaren i en classificaren els arguments - tipus-, i, des d'una altra òptica, Propp (1928), que veia que estructuralment ocorre el mateix: les rondalles tradicionals són universals.

És per això que qualsevol estudi a l'entorn d'aquest tema que vulga tenir rigorositat científica ha de passar per ací. Arreplegar una rondalla i transcriure-la és salvar-la de l'oblit; arreplegar una rondalla, transcriure-la i situar-la en un catàleg és tractar-la com un producte científic, com ho faria un biòleg amb un animaló desconegut. 
Actualment, el catàleg més important i que sembla tenir més validesa i acceptació entre la comunitat d'estudiosos de l'etnopoètica parteix d'un inicial d'Aarne (1910) que completà i amplià Thompson (1928) i que donà lloc al sistema Aarne-Thompson (1961, que se sol simplificar com Aa-Th) i que, en el nostre segle, Uther (2004) ha actualitzat i perfeccionat en l'anomenat ATU, que prové de les inicials dels tres autors. Aquest serà el nostre marc de referència.

Ara bé, si hem de treballar la nostra realitat i les nostres rondalles, es fa necessària una catalogació més acotada a la cultura catalana. En aquest sentit, és imprescindible el treball d'Oriol i Pujol (2003), un índex tipològic de les rondalles catalanes (digitalitzat i ampliat en la base de dades del Rondcat, amb el sistema ATU) que ens permetrà saber si les nostres troballes es poden documentar o no en algun punt de la geografia catalanoparlant. Per al cas valencià, a més, és obligatori passar per Beltran (2007) que, amb el seu estudi exhaustiu, fa una antologia i un catàleg de les rondalles valencianes publicades fins al moment.

Tots aquests catàlegs han estat possibles perquè hi ha hagut «recolllectors», folkloristes (com Francesc Martínez, que citem a l'inici d'aquest treball) que s'han preocupat d'arreplegar aquesta narrativa oral perquè no caigués en l'oblit. En una societat poc alfabetitzada i sense uns mitjans de comunicació tan potents com els actuals, l'entreteniment i l'ensinistrament —que són les dues màximes d'aquests mitjanss'havien de vehicular d'una altra manera: en les relacions personals. Per tant, oralment, entre les diverses generacions. En es segles XIX i XX hi va haver un interès collectiu per recuperar i posar per escrit (verba volant, scripta manent) aquesta cultura ancestral, i és per això que comptem amb figures tan decisives per a l'etnopoètica catalana com Milà i Fontanals, Jacint Verdaguer o Joan Amades per a Catalunya o Antoni Maria Alcover per a les Illes. Les circumstàncies sociopolítiques, però, no han estat gaire favorables per als valencians, i encara sort que comptem amb figures com Francesc Martínez o, ja posteriorment, Enric Valor, les aportacions dels quals, encara que no tan voluminoses com les d'Amades o Alcover, mai no seran prou pagades.

Valor ja se n'adonava: quan ell es posava a arreplegar rondalles, moltes li arribaven esquarterades, mutilades, combinades, confuses, i ell 
en va haver de fer una tasca de restauració que, en algun cas, va arribar a ser reconstrucció. Si això era així en els temps de Valor, si Valor encara podia restaurar allò que li arribava, avui recuperar rondalles és fer un exercici d'arqueologia. El patrimoni narratiu oral es troba en un perill d'extinció seriosíssim: abocats a un presentisme (viure el present) que ens fa perdre la memòria, vivint com vivim en una societat en què els models de comunicació han canviat completament i en què l'escolta passiva de la televisió ha substituït el diàleg intergeneracional i la transmissió de llegendes i rondalles, es constata, i cada vegada més, una interrupció d'aquesta transmissió. És urgent, doncs, l'arreplega de rondalles: dins d'unes dècades hauran deixat d'existir com a fenomen espontani.

Per allò que acabem d'assenyalar, és a dir, pel fet que als valencians ens ha mancat una figura compiladora potent a finals del XIX o principis del XX, sembla haver-hi, també, una certa descompensació pel que fa a les rondalles conservades al País Valencià respecte de Catalunya i les Illes, si bé és cert que en les últimes dècades aquesta mancança s'ha vist reduïda (BORJA: 2011, 27). Sempre serà positiu, doncs, el fet de trobar noves rondalles valencianes que se sumen a les que hem aconseguit conservar. Aquest serà, com veurem, un dels nostres objectius. Ara bé, el que és interessant fer veure és el fet que, dels tipus ATU valencians documentats, el 91\% coincideixen amb d'altres tipus ATU conservats a altres regions del domini lingüístic (BORJA: 2011, 28). Això no pot ser casualitat: el nostre origen romànic és comú, i la transmissió d'una llengua no és solament la transmissió d'un codi lingüístic, sinó també de tot un món cultural que hi subjau. És d'ací que es desprèn un segon objectiu, que ja avancem: trobar nous ATU que enllacen els valencians amb la resta de territoris del domini lingüístic. Si les altres regions comparteixen tipus, per què no hi deuen ser al País Valencià? Potser, simplement, ningú no els ha transcrit —de moment. Aquesta és, doncs, la nostra tasca. 


\section{DUES RONDALLES TAMBÉ VALENCIANES}

\subsection{L'ARREPLEGA. OBJECTIUS I METODOLOGIA}

Atesa la importància ja explicada de rescatar al País Valencià aquelles rondalles que romanen encara en la memòria collectiva, la investigació, ja ho hem dit, parteix amb un doble objectiu: d'una banda, arreplegar, per via oral, rondalles valencianes encara no documentades que, per les dimensions del nostre treball, es redueixen a escala local; d'altra banda, trobar, dins de les narracions arreplegades, aquelles que connecten amb la resta de la cultura catalana. La intenció, per tant, passa per la necessitat de continuar la tasca sempre incompleta de recuperar el patrimoni etnopoètic valencià, però té l'afegit de demostrar, amb aquests nous grans d'arena que són les rondalles que transcriurem, tot allò que el professor Borja ja constata i resumeix d'aquesta manera:

La conclusió, per tant, apunta a una constatable homogeneïtat del patrimoni etnopoètic als diferents territoris de llengua catalana. El fet —així ens ho sembla- transcendeix l'interés de l'anècdota i ens recorda que, a pesar de les diferències certes i de les disputes fictícies, valencians, catalans i balears -els pobladors de la Franja, del Carxe, d'Andorra, de la Catalunya Nord, de l'Alguer- no solament comparteixen una història comuna, uns signes d'identitat, uns interessos econòmics, un sistema lingüístic o el blau inefable de la mar, sinó també les formes de la imaginació, de la meravella, de la fantasia (2011, 31-32).

Per dur a terme aquests objectius ens ha calgut partir de la localització dels informants i la sollicitud directa o indirecta de rondalles tradicionals, a continuació n'hem fet un enregistrament sonor i llavors n'hem seleccionat, entre les rondalles enregistrades, aquelles que no apareixen documentades al País Valencià en Oriol i Pujol (2003), que hem transcrit fonèticament. Aquesta selecció final ha permès acotar la nostra anàlisi i apuntar cap als objectius descrits; i la transcripció fonètica respon al fet de no voler alterar-ne cap detall lingüístic i també, és clar, al tractament científic que mereix.

L'arreplega s'ha dut a terme a la Vila Joiosa l'any 2010 i ha comptat amb diversos informants; tanmateix, tan sols dos interessen per al nostre estudi, un per cada rondalla no documentada encara al País Valencià: Domingo Soriano, home, jubilat, de 85 anys durant el moment 
de l'entrevista, i Josefa Lloret, dona, mestra, ${ }^{114}$ de 50 anys durant el moment de l'entrevista. Tots dos, és clar, naturals d'aquest poble.

\section{2 «EL SOLDAT DE LA MOTXILLA»}

Aquesta rondalla, que ens narrà Domingo Soriano (v. \$2.1) fou arreplegada el 9 de desembre de 2010 i és del tipus 330B (Aa-Th), que Uther remet a l'́ndex ATU 330. Si els tipus Aa-Th 330A-D es fonen, com proposa Uther, en un sol índex, llavors les mostres valencianes són força nombroses, com es pot veure en el catàleg de Beltran (2007: 593 594), i faríem coincidir «El soldat de la motxilla» amb el que Beltran cataloga com «El ferrer sarrió» (ATU 330, The Smith and the Devil; AaTh 330, The Smith Outwits the Devil) i també amb «La tia Misèria» (AaTh 330D, Bonhommme Misère). Tanmateix, si mantenim les diferències d'Aarne-Thompson, el resultat és més precís i s'evidencia una manca de documentació del tipus 330B al territori valencià, que sí que es documenta en el Rondcat a Mallorca.

L'argument de la rondalla arreplegada explica que un soldat, de camí a casa, és caritatiu amb homes pobres per tres vegades. A la tercera se li apareix el Nostre Senyor i li explica que tan sols el posava a prova i, per les bones accions, el recompensa amb una motxilla que té la propietat de fer allò que se li demana. El soldat accepta el regal i fa nit en un mas abandonat on hi ha dimonis. Quan el soldat sopava, els dimonis escupen sobre el menjar $\mathrm{i}$, quan ho tornen a intentar, el soldat, amb un crit en castellà, aconsegueix que els dimonis s'enganxen a la motxilla $i$ no es puguen moure. Els allibera a l'endemà. Quan passa el temps i el soldat ha de morir, séns informa que Nostre Senyor li havia comunicat que acceptar la motxilla implicava anar a l'infern. Ell hi va, però no l'admeten: els dimonis li han pres por. Llavors puja al cel i Nostre Senyor i sant Pere acorden que es quede darrere de la porta del cel.

A diferència del que sol ocórrer, aquesta rondalla ens ha estat

\footnotetext{
${ }^{114}$ El fet que aquesta informant siga mestra podria haver enterbolit l'anàlisi, des del punt i hora que podria conèixer rondalles ben diverses de procedència no necessàriament valenciana, o que li haguessen arribat per transmissió escrita. És per això que en el moment de l'entrevista, en aquest cas, n'hem explicitat les condicions.
} 
transmesa sense vacillacions de manera gairebé totalment íntegra. Només ens falla un detall, que potser l'informant també detecta: el soldat és caritatiu i per això té la recompensa de la motxilla; però, per què això ha d'implicar anar a l'infern? Això, en l'ATU 330, es resol amb un protagonista que, al principi del relat, ha venut l'ànima al Diable, cosa que també faria coherent la nostra narració.

Vegem-ne la transcripció fonètica:

[el sol'dad de la mo'ţiKa 'ez 'uno da'si/ de la 'vi/ da'si / ai' ke sen 'va 'nar al ser'visi// jen'tonses/ en el ser'visi/ 'no a'vien 'atra 'kozo 'mes ke 'kwant aka'baven el ser'visi sen te'nia ke 'vinðre a 'kaza a 'peu// i [...] sol'dad li 'van do'nar/ pal ka'mi de/ 'don es'tava el ser'visi a'si a la 'vila/ li 'van do'nar 'un 'pa/ pa ke a'nara 'kwant [...] eskam'pava ke men'đzara/ 'perke/ 'perke te'nia ke es'tar 'dos 'dies pa 'vinðre/ 'kera a 'peu/ 'no a'vien [...]// 'bweno/ akomen'sem per 'eife// 'je $K$ sen 'va 'vinðre/ i sen ve'nia kare'tera/ per la kare'tera/ jan'kontra 'un po'ßret// i li diu/ as'kolte/ vos'te 'nom dona'ria 'una li'mozna?/ el po'ßret// i 'diu/ 'si/ 'ome/ 'jo li 'done 'una li'mozna/ ei/ 'jo li 'done 'una li'mozna 'perke 'mire/ 'jo 'vink del ser'visi i re'zulta ke 'man do'nat 'um 'pa// i 'mire/ lin dona're 'un 'troz/ a vos'te/ jel sol'dad li 'dona 'un 'troz de 'pa// 'ei $\int e$ 'ez el 'kwento la mo'triKa/ 'jara u vo'ras// li 'dona 'un 'troz de 'pa al po'ßret // se'yis per a'vant// a 'latra 'volto/ 'un 'atre po'ßret// i 'diu el sol'dat/ diun/ tre/ em keda're 'sense 'pa/ i 'diu/ pos 'donem 'un 'atre tro'set/ 'perke 'jo 'sok m: po'ßret/ 'no 'se 'kwantos// 'bweno/ se' yis// 'pero a la ter'ser

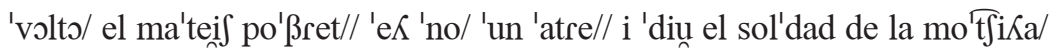

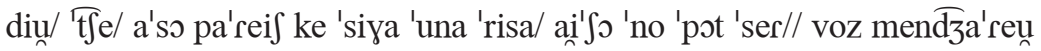
'todz el 'pa i 'jom keda're 'sense 'res// 'perke 'eK eu do'nava// diu / 'mira/ 'vaig a 'dili la veri'tat// el ke li 'a i'Jit 'jo 'trez 'voltes/ 'jo 'no 'sok nin'gun 'poßre/ 'jo 'sok el 'nostre se'nor// ko'Kons [...]/ diu/ 'jo 'sok el 'nostre se'nor// 'ara vos'te/ kom 'a 'vist ke vos'te 'te 'una bon'dat 'bono/ 'ara vos'te em 'te ke 'dir 'kez lo ke 'vuK 'jo li dona're 'una 'kozo ke li 'dona a vos'te lo ke 'vol// i 'diu el sol'dat/ 'E/ vos'te di'ra// i diu / 'poz 'mira/ 'vaig a do'nate 'una mo't $\mathrm{t} i \kappa \mathrm{a} /$ 'una mo't $\mathrm{t} \mathrm{i} \kappa \mathrm{a}$ ke vos'te/ lo ke li dona'ra/ liu demana'ra a la mo'tfiKa i liu dona'ra// lo ke li demana'ra a la mo'triKa/ liu dona'ra// i// 'tfe/ 'mol kon'tent// el po'ßret 'keða en ke/ no 'era el po'ßret/ 
era el se'nor/ li 'va do'nar la mo't $\mathrm{Ti} K \mathrm{Ka}$ jel sol'dat se'yis// 'pero a'plega a 'un 'poßle/ kom es'tava 'Kark/ a'plega a 'un 'poßle kes te'nia ke ke'ðar/ i 'va bus'kar a lal'kalde pa ke li di'yera la 'kaza pa/ pa ke'ðase/ i 'diu lal'kalde/ 'diu/ 'si/ 'jo ez 'done la 'klau// 'pero a'i/ 'todz es ke/ 'todz es 'kentren en la 'kaza ez 'moren// 'T e/ kom?// i 'diu/ 'si/ a'Ki ez 'moren 'tots/ 'perke re'zulta ke de 'nit 'ifen 'unz di'monis// i:/ i diun/ 'bweno/ poz

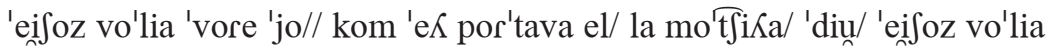
'vore 'jo// al 'rato kes'taval sol'dad de 'nit 'ja 'dinz la 'kaza es 'sent/ 'bom/ 'bom/ 'dald de la 'kambra// ja'baisen 'tres// jel sol'dat es'tava 'fense 'una mi'keta de men'dzar en 'un/ en 'un pero'let/ 'walgo/ jel sol'dad 'diu [...] i 'diu// no to'keu 'rez dai'So/ ke sa'ßreu 'jo 'ki 'sok// ja'keKs/ al ra'tet

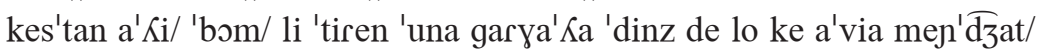
lo ke a'via 'fet el sol'dat// diu/ 'no 'kore// i sem 'puđzen a lez as'kales per a'munt// 'diu/ no tor'neu a bai'Sar/ ke si abai'Seu voz 'mate/ e?// el sol'dat 'tira a' $K \mathrm{O} / \mathrm{sen}$ 'torna a 'fe el mej'dzar i al ra'tet a'ke $K$ s per a'va $K / /$ ja'pleyen a'Ki i 'diu el sol'dat/ 'ara voz anga'neu్n// 'a vo'ras// i 'diu el sol'dat/ 'kwan 'ja 'naven a ti'rali el/ a Kan'sali el men'đzar/ 'diu// 'todoz 'dentro de mi mot tyi $\kappa \mathrm{a} / /$ i 'tots/ 'dinz de la mo to $\mathrm{Ti} \kappa \mathrm{a}$ ke li 'dona el se'nor// say'gantfen a'Ki i 'no 'pujen dezangan'tfase// jes 'keden angan tTatz a' $K i$ 'dinz

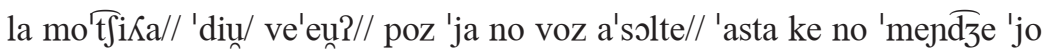

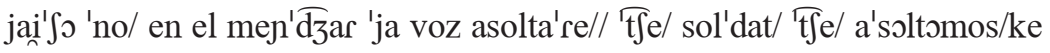
mo'zatroz/ no se 'kwantos/ 'som/ 'som de lin'fern// [...] di'moni de lin'fern/ 'diun/ 'bweno/ 'sjeu kom vuK'geu/ / 'jo 'no voz a'solte// 'bweno/ es 'fa de ma'ti jelz a'solto// jen'ton[ses] re'zulta kel sold'at sen 'va a 'kaza// 'pero 'vel mo'ment kel sol'dat ez 'mor// de 'veא o 'no 'se/ el sol'dat ez 'mor// jal mo'rirse el sol'dat/ kom el se'nor li 'va 'dir ke li do'nava la mo'trika 'pero kal 'sel 'no 'puja 'nar/ te'nia ka'nar a lin'fern/ jen'tonses el sol'dad diu/ 'bweno/ poz me nani're a lin'fern// pero a'plega a lin'fern 'jeren els ke li es'tava 'e $\delta / /$ jes'tava el 'koijo lin'fern/ ke 'tu las sen'tit nome'nar/ el 'koifo lin'fern es'tava a'Ki/ i li 'diwen a a'ke $K /$ 'diu/ Tfe/ al sol'dad 'no li o'ßriu/ ke mos 'va po'zar 'dins la moți $\mathrm{ta} / /$ 'tfe/ per la'mor ðe deu/ al sol'dat 'no li o'ßriu// jen'tonses el sol/ el/ el soldad 'diu/ 'tye/ 'jara 'ke 'fat $\overline{2}$ // 'ara 'no 'puk a'nar a kae

115 [kae]: 'cap de'. 
'pwesto// jen'tonses sen 'va

tor'nar al 'sel// i li 'va 'dir/ i li 'va 'dir al/al se'nor ja 'sant 'pere/ kes'taven $a^{\prime} K \mathrm{i} / /$ 't $\mathrm{tg}$ e/ em 'pasa a'so/ a 'nat a lin'fern jel 'koijo 'nom 'deifa n'trar/ 'perke li 'vais 'fer la pa'sa la mo't jiKa i 'nom 'deifa n'trar// i li 'diu 'sant 'pere al se'nor/ 'diu/ 'mira/ 'pozolo a' Ki da'rere la 'porto ja'kaben// jes 'va po'zal sol'dad da're la 'porto// i a'i sa'kabal 'kwento// ai'so 'era el 'kwento del sol'dad de la mo'tri $\mathrm{i} \mathrm{a} / /]$

\section{3 «EL TEULADÍ I EL "RABIBLANC"116»}

Josefa Lloret (v. \$2.1.) ens narrà aquesta rondalla que vam arreplegar el 8 de desembre de 2010 i remet a l'ATU 245 (The Tame Bird and the Wild Bird). També es podria dir que remet a l'ATU 112 (Country Mouse visits Town Mouse), ja que, en realitat, els dos tipus semblen variants del mateix conte, però amb animals protagonistes diferents. En el nostre cas es tracta d'ocells i, per tant, s'acosta més al 245. En qualsevol cas, ni l'un ni l'altre es documenten encara al País Valencià, i sí a Catalunya i la Franja d'Aragó, i també a les Illes Balears si hi incloem l'ATU 112. Per tant, es feia necessària aquesta contribució: es tracta d'una rondalla que, a partir d'ara, ja es documenta a tots els grans territoris catalanoparlants peninsulars.

L'argument explica que un teuladí, ocell urbà, fa notar a un «rabiblanc», ocell de muntanya, que li deu ser ben difícil aconseguir el menjar. Per això, li proposa d'anar al molí, però, quan hi són, arriba el propietari i intenta acaçar-los; el teuladí, com que és menut, aconsegueix escapar-ne, però el «rabiblanc» n'ix malmès. Llavors aquest decideix tornar al seu habitatge normal.

Potser per la situació extraordinària del context en què es narra la rondalla, trobem a faltar la moralitat explícita típica de faules com aquesta, és a dir, una cosa com «és preferible la pobresa amb seguretat al

\footnotetext{
${ }^{116}$ No hem aconseguit documentar aquest mot enlloc, però, segons la informant, es tracta d'un ocell de grandària mitjana, tot de color negre i amb el carpó i la cua blanca. Uns altres vilers ens en confirmen l'existència. Segurament es tracta de la «merla cuablanca» (oenanthe leucura), que, a més, sembla ser coherent amb l'argument de la història pel fet que sol habitar en llocs rocosos i, per tant, allunyats de zones urbanitzades.
} 
luxe amb risc». En qualsevol cas, la narració ací també es conserva íntegra, com es pot observar en la transcripció fonètica:

['pwe:s/ 'diu ke a'via 'un taula'i i 'un rabi'ßlank/ 'jo 'no' re'korðe 'molt 'be ke/ jale'zorez el de/ el:/ el rabi'ßlank 'sempre 'a vif'kut en la mun'tana [...] 'mes sal'vađ̧ze jel taula'i 'es de:/ de 'poßle/ i 'va areple'yant mo'Ketes de 'poßle/ i 'tal// i el rabi'ßlank/ poz lo ke 'piKa per la mun'tana// to'tal/ ke el taunla'i li 'diu/// i 'tu 'viunz a'si/ a 'soles/ i/ i ai' i/ i/ i 'res/ 'tfiko/ 'vineten en 'mi al mo'li i vo'ras 'tu 'kwand de 'blat te'nim

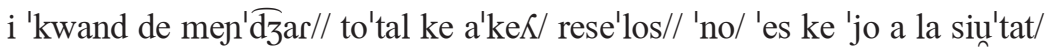
'jo a' $\mathrm{Ki}$ 'no// 'si/' tu 'vineten i vo'ras 'kom mej'đ了em de 'be a' $K \mathrm{i}$ 'blat al mo'li/ i 'tal// to'tal/ ke el rabi'ßlang li 'fa 'kaz al taula'i i sen 'va pak a la suún'tat/ pak a:l 'poßle/ sen 'van al mo'li/ ko'mensen a rebo'lar per 'dald del mo'li/ jel taulai'net 'es đfuku'tiu jen se' yiða sen 'va 'nar a bus'kar el 'blat// 'pero el moli'ner/ ke 'va 'vore 'un par'ðal 'tan 'gran revo'lant per a'Ki/ 'diu/// 'a/ se'nor// a'so 'kes?// 'va 'traunre lasko'peta/ bom/ bom/ askope'ta// el 'va mam'prenðre ja'ke $\Lambda$ li 'va 'dir al taula'i// 'fui:t// 'je:/ a mi karas'kal me 'vwelvo// i sen 'va tor'nar pak a sa 'kaza/ perke aj'ऽっ de ke li ti'raren $[\ldots]$ no://]

\section{CONCLUSIONS}

Les rondalles arreplegades, doncs, responen al doble objectiu de salvar-les de l'oblit i d'observar narracions valencianes encara no documentades i que, a més, coincideixen amb tipus documentats en unes altres zones del domini lingüístic. En el primer cas es tracta del tipus 330B segons el sistema Aarne-Thompson, del qual, fins ara, només se'n tenia notícia a Mallorca; en el segon cas, es tracta del tipus ATU 245, present, fins el moment, a Catalunya i la Franja i, si comptem l'ATU 112 com la mateixa rondalla, també a les illes Balears. Era important, doncs, demostrar que al País Valencià també tenim aquests tipus: lliga amb la idea d'una cultura comuna, compartida encara avui en les manifestacions espontànies de la literatura oral. El nostre poble és el propietari d'aquestes narracions i no es pot permetre el luxe de perdre-les. És per això que cada vegada es fa més important transcriure aquest patrimoni, perquè l'escrit, com la perera de la tia Misèria, com la motxilla del soldat, 
en garanteixen la conservació, garanteixen que aquest patrimoni s'aferre a la vida. Almenys, fins que el propietari ho vulga.

\section{BIBLIOGRAFIA}

AARnE, Antti (1910): Verzeichnis der Märchentypen, Hèlsinki, Suomalainen Tiedeakatemia.

Aarne, Antti i Stith Thompson (1928): The Types of the folk-tale, Hèlsinki, Suomalainen Tiedeakatemia.

- (1961): The Types of the Folktale: A Classification and Bibliography, Hèlsinki, The Finnish Academy of Science and Letters.

Beltran, Rafael (2007), Rondalles populars valencianes. Antologia, catàleg $i$ estudi dins la tradició del folklore universal, València, Publicacions de la Universitat de València.

BORJA, Joan (2011): «Etnopoètica i territori: unitat i diversitat de la rondallística catalana», en Dari ESCANDELL i M. Jesús FRANCÉS (ed.), Etnopoètica $i$ territori: unitat $i$ diversitat, Càller, Arxiu de Tradicions de l'Alguer.

MARTíneZ, Francesc (1920): Còses de la meua tèrra (la Marina). Segona tanda, València, Fills de Francés Vives Mòra.

ORIOL, Carme (2002), Aproximació a l'etnopoètica. Teoria i formes del folklore en la cultura catalana, Valls, Cossetània.

Oriol, Carme i Josep M. PujOL (2003): Índex tipologic de la rondalla catalana, Barcelona, Departament de Cultura de la Generalitat de Catalunya.

Propp, Vladimir (2006): Morfología del cuento, Madrid, Fundamentos [la primera edició és de 1928].

Rondcat: cercador de la rondalla catalana, Arxiu de Folklore, Departament de Filologia Catalana de la Universitat Rovira i Virgili. Darrera consulta: 15/12/2011 URL: <http://www.sre.urv.cat/rondcat>

UTHER, Hans-Jörg (=ATU) (2004): The Types of International Folktales. A Classification and Bibliography. Based on the System of Antti Aarne and Stith Thompson, 3 vols., Hèlsinki, Academia Scientiarum Fennica. 